\title{
COMPRARTES?: DESENVOLVIMENTO DE UMA INTERFACE GRÁFICA PARA APLICATIVO DE E-COMMERCE DE PRODUTOS ARTESANAIS
}

\section{COMPRARTES?: GRAPHIC INTERFACE DEVELOPMENT TO AN E- COMMERCE APP OF CRAFTWORK PRODUCTS}

MARTINS, Elisa Batista Conrado (1); PAULA, Thyago Reis (2); GONÇALVES, Vivianne Ferreira (3); SILVA, Yasmim Mariana Baía (4); ALENCAR, Yuri Samuel de Lima

(1) Universidade do Estado do Pará, Graduando em Bacharelado em Design (UEPA) e-mail: elisabatistacm@gmail.com

(2) Universidade do Estado do Pará, Graduando em Bacharelado em Design (UEPA) e-mail: thyreispa@gmail.com

(3) Universidade do Estado do Pará, Graduando em Bacharelado em Design (UEPA) e-mail: viviannefg18@gmail.com

(4) Universidade do Estado do Pará, Graduando em Bacharelado em Design (UEPA) e-mail: yasmimbsilva.11@gmail.com

(5) Universidade do Estado do Pará, Graduando em Bacharelado em Design (UEPA) e-mail: yalencar76@gmail.com

Palavras-chave: Usabilidade, Interface, Artesanato.

Este artigo tem como objetivo empregar os requisitos ergonômicos teóricos em uma interface gráfica para otimizar a usabilidade de um aplicativo voltado para o comércio eletrônico de produtos artesanais paraenses. O propósito partiu da exigência de projeto delimitada pelo tema "Entre o Rio e a Rua", dessa forma se delineou a proposta de conduzir o artesanato das ilhas e interiores para as ruas da cidade, inicialmente visando ser uma ferramenta facilitadora do contato entre os atores sociais (artesãos, vendedores e consumidores) além de auxiliar o comércio local. Como resultado, tem-se um projeto de interface gráfica para aplicativo de e-commerce, no qual valoriza o público-alvo e seu contexto, além de trabalhar o meio digital como ferramenta essencial para o aprimoramento do mercado artesanal local.

Key-words: Usability, Interface, Craftwork.

The article's goal is to apply theoretical ergonomic requisites for a graphic interface in order to optimize the usability built for an ecommerce app of handcrafted products from Pará. The purpose was based on the project requirement delimited by the theme "Between the River and the Street" in order to be a tool to support the contact between social actors (artisans, sellers and consumers) as well to assist local commerce. As a result, it has a graphical interface design for an e-commerce application, which values the target audience and its context as well 
as use digital media as an essential tool for the improvement of the local handcraft market.

\section{Introdução}

A população global está cada vez mais conectada devido ao aumento no uso de dispositivos móveis e acesso à internet. De acordo com Época Negócios (2016), quando se trata de smartphones, a expectativa é que o Brasil tenha um acréscimo de $40 \%$ nas vendas durante os anos de 2017/18, já os tablets podem ter crescimento de $7 \%$ em relação à 2015. Nos dias atuais, o smartphone "se tornou a principal forma de acesso à internet" (ÉPOCA NEGÓCIOS, 2016). Em 2012, 80\% das pessoas já haviam pesquisado produtos ou serviços através de um dispositivo móvel e $88 \%$ já procuraram por informações locais (GOOGLE INC., 2012). Consequentemente, isso mostra que esse campo digital e de serviços deve ser mais explorado para atender a demanda crescente da sociedade.

Nesse contexto, buscou-se utilizar a tecnologia como uma ferramenta para difundir a cultura brasileira. No contexto de um aplicativo de $e$ commerce, o qual há funções complexas, os requisitos de usabilidade aprimoram a experiência do usuário de diferentes graus de domínio sobre aplicativos. Para o tema do projeto, que se trata do cenário do artesanato no Pará, pensou-se em contribuir com o comércio e a manutenção de uma cultura. Seguindo a metodologia e princípios expostos pelos autores Cybis, Betiol e Faust (2010) para o desenvolvimento de interfaces, foram aplicadas etapas desde análise contextual, especificação e concepção até a proposta final do aplicativo tendo como objetivo criar um projeto gráfico que atenda às necessidades dos possíveis usuários.

\section{Desenvolvimento}

O projeto foi segmentado em: requisitos de projeto, métodos de coletas de dados e montagem dos testes. Na fase criativa para definição de aspectos simbólicos, estéticos e identificação de cenário, e demais aspectos do projeto conceitual, foram aplicadas as metodologias dissertadas por De Moraes (2010), Baxter (1998) e Niemeyer (2003).
Para avaliação dos testes e embasamento teórico para definição da natureza deste, fez-se uso dos conceitos propostos por Iida (2005).

\subsection{Técnicas de análise contextual}

Para a realização do projeto foi indispensável identificar e analisar primeiramente o cenário. Desta forma, a aplicação desta técnica torna-se necessária para delinear as oportunidades de atuação do aplicativo, cujo tema é voltado para o artesanato. Tendo isso em vista, foram realizadas pesquisas de campo em pontos turísticos da cidade de Belém, como o Ver-o-Peso, a Estação das Docas e a Praça da República, os quais apresentam uma grande concentração de turistas e artesões. Nesses locais, foram realizadas entrevistas com artesãos e comerciantes do artesanato. Assim como os artesãos, alguns clientes e/ou pessoas que se interessam por artesanato também foram consultados, de modo a ampliar o conhecimento com relação às necessidades do outro público visado no projeto: os consumidores. Aos potenciais consumidores, turistas e pessoas da área criativa foi aplicado, também, um questionário estruturado visando os perfis de uso. A coleta de dados buscou identificar a característica dos consumidores de artesanato. Além disso, pretendeu-se assimilar os dados demográficos gerais e preferências na aquisição de produtos artesanais.

A partir dos dados extraídos das entrevistas, foi possível identificar certas carências e oportunidades de atuação. Após essas pesquisas, foram identificadas algumas necessidades:

a) Dificuldade de venda de itens grandes devido ao transporte; b) Alguns artesãos reconhecem que seu modo de divulgação do trabalho deixa a desejar; c) Necessidade de expansão de negócio; d) Dificuldade de aquisição de produtos de artesanato ligados a locomoção até os pontos de venda; e) Dificuldade de comunicação com turistas estrangeiros.

Diante disto, foi definido o principal propósito do projeto: promover o artesanato através do $e$ -
Realização:
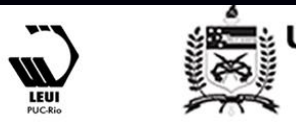
commerce - esse objetivo poderia ser alcançado por meio de uma dinâmica mais similar a uma rede social - na qual há essa interação mais próxima desses atores.

\subsection{Técnicas de especificação}

Consistem em gerar, analisar e organizar requisitos para novos projetos, seja ele um produto, sistema ou aplicação (CYBIS; BETIOL; FAUST, 2010).

Como público-alvo, definiu-se que os usuários diretos estariam divididos em dois grupos, o primeiro corresponde aos artesões - aqueles que produzem e vendem o seu artesanato ou que apenas vendem - e o segundo seriam as pessoas que já adquirem produtos artesanais. Há também os indiretos, compostos pelos auxiliares responsáveis pela manutenção do serviço, possíveis auxiliares no uso do aplicativo e pessoas com interesse em saber apenas o local de compra.

Dentro das técnicas de especificação para identificar as principais necessidades projetuais, foram-se depreendidos, no papel de um aplicativo de comércio digital, os seguintes requisitos:

a) Apropriada disposição dos produtos e pontos de venda; b)Opções de idiomas (Inicialmente português, inglês e espanhol); c)Espaço para informação do vendedor e do produto (como significado e materiais utilizados); d) Ícones em tamanho agradável e os principais em destaque; e) Funções claramente definidas; f) Interface simples e objetiva; g) Possuir uma hierarquia visual; h) Linguagem textual e tipografia adequada para o público; i) Uso de imagens dos produtos; j) Campo para apresentação de feedback; k) Apresentação de filtros para organização eficiente - categorias de artesanato; 1) Adequada paleta de cores; $\mathrm{m}$ ) Sistema que garanta a segurança na compra e venda.

Ainda sobre os requisitos de usabilidade, é necessário identificar o contexto de uso do produto. Por ser uma interface gráfica voltada para um aplicativo, quando utilizada, a atenção dada a ela, por parte do usuário, recebe interferências sensoriais do ambiente, além da própria complexidade da informação (MANDEL, 1997 apud SOUZA; SPINOLA, 2006). Outro fator que influencia na performance do usuário é o seu próprio grau de experiência e personalidade (SHNEIDERMAN, 1998 apud SOUZA;

SPINOLA, 2006). Como os usuários possuem um grau de experiência diversificado, alguns deles não têm tanta familiaridade com a tecnologia e o uso de aplicativos de e-commerce, é importante que o aplicativo ofereça instruções de uso e apresente um campo de ajuda para os que venham a ter maiores dificuldades, além de adotar uma linguagem direta e familiar ao público.

Portanto, para que o usuário tenha um grau de satisfação alto, é necessário adotar alguns requisitos no projeto do aplicativo. $\mathrm{O}$ aplicativo prevê tarefas diversificadas com diferentes especificidades nas suas funções, tais como os mecanismos de e-commerce, comentários e mapeamento, aos quais devem atender determinados requisitos de tempo de tarefa e transmitir segurança para a execução de uma ação, para que assim seja confiável. Então, para determinar essas exigências, foi utilizado os dados coletados anteriormente como a análise dos similares, considerando os pontos positivos como parâmetro para a construção da interface gráfica do aplicativo, em que o intuito é de não gerar constrangimento ou estranheza no público.

O projeto da interface no desenvolvimento desse aplicativo é norteado por princípios de um bom layout e de arquitetura da informação, respaldado pelas leis de usabilidade de Krug (2006) e subsidiados pelas especificações de contexto de uso (CYBIS; BETIOL; FAUST, 2010, p. 168), além das referências de planejamento de uma interface competente. Ou seja, a identidade visual do aplicativo deve apresentar uma unidade, as funções deverão estar claras e articuladas entre si, assim como as cores, ícones e sons devem ser coerentes quanto a mensagem pretendida, e com isso auxiliar na tomada de decisão.

Outras técnicas utilizadas para determinar os requisitos de usabilidade foram os cenários de uso e as personas. Nos cenários de uso estabeleceramse quatro situações, que consistem em pequenas narrativas de acontecimentos envolvendo o uso do aplicativo, sendo situações que foram identificadas 
$16^{\circ}$ USIHC - Congresso Internacional de Ergonomia e Usabilidade de Interfaces Humano Computador

CINAHPA | 2017 - Congresso Internacional de Ambientes Hipermídia para Aprendizagem.

na coleta de dados ou que poderiam vir a acontecer. Estes apresentam casos envolvendo tanto os compradores (brasileiros e estrangeiros) como os artesões/vendedores e procuram criar situações que teste a interface e a usabilidade do aplicativo. Para o desenvolvimento das personas, foi considerado o resultado da pesquisa quali/quantitativa com o público-alvo do aplicativo. Elas se dividem em quatro perfis: a da consumidora jovem, a senhora, e dois artesãos. Foi dado a eles nome, idade, escolaridade, profissão, hobbies e outras características que ajudam a determinar os usuários pretendidos e assim direcionar a interface de acordo com o seu repertório e características cognitivas.

Ademais, foram construídos três painéis semânticos, propostos por Baxter (1990). O painel de estilo de vida contribuiu para a construção das personas. O painel do tema visual apresenta imagens de produtos com formas, cores e organizações interessantes para o aplicativo. Já o painel de expressão do produto visa expressar, através de imagens sem relação direta com o tipo de produto a ser projetado, alguns dos conceitos que o aplicativo pretende transmitir ao usuário durante seu uso. Por fim, a técnica de geração de ideias chamada "encontrando uma voz visual" definida por Niemeyer (2003), tinha o objetivo de identificar os principais valores do projeto e contribuir para o desenvolvimento da interface.

\subsection{Técnicas de concepção}

As técnicas de concepção são um conjunto de ferramentas para respaldar a construção de um projeto de interface (CYBIS; BETIOL; FAUST, 2010). Neste momento do projeto, foram empregados o Brainstorming, que serviu para definir os objetivos principais das funções primárias e secundárias do aplicativo, e em seguida o diagrama de afinidade, para que se possa auxiliar o reconhecimento de funções dentro do aplicativo, além de prever uma ordem mais lógica de navegação (CYBIS; BETIOL; FAUST, 2010).

Através do conhecimento dessas informações, foi elaborado um Storyboard (narrativa gráfica), o qual permite representar visualmente uma sequência de acontecimentos com o intuito de especular o ato de interação do usuário (CYBIS; BETIOL; FAUST, 2010). Nela, foi representada uma situação na qual uma compradora de artesanato vê um produto interessante, vê a avaliação positiva de um amigo dessa mesma rede, e efetua a compra.

No contexto de projeto de interface gráfica, a prototipagem tem o intuito de fazer uma verificação sobre os resultados fornecidos pelas técnicas empregadas anteriormente, em uma fase de baixa fidelidade e outra, de alta. Inicialmente, foram desenvolvidas 38 telas para servirem de protótipos de baixa fidelidade, todas relativas às tarefas desempenhadas pelo aplicativo para serem testadas pelos usuários, pois "os protótipos de baixa fidelidade podem ser validados por representantes de usuários em simulações de uso mais realistas [...]" (CYBIS, BETIOL, FAUST, 2010). Estes usuários possuíam perfis diferentes entre si, em relação aos seus graus de domínio com um smartphone.

No teste de baixa fidelidade, foi proposto um questionário aos usuários com questões pertinentes ao aplicativo, e no final do uso, pedido que eles relatassem a experiência com suas próprias palavras, de modo que fosse possível traduzir o relato na linguagem do teste fisiológico e do teste antropométrico. Os dados extraídos sobre as telas foram divididos em "pontos positivos" e "pontos negativos", conforme as impressões que os usuários informaram. A partir desses pontos, os próximos protótipos foram desenvolvidos já levando em consideração a análise dos entraves identificados. Por meio desses protótipos, "torna-se possível obter medidas de usabilidade (eficácia, eficiência e satisfação) em testes em situações de uso e verificar se as medidas obtidas se aproximam do especificado. Frequentemente será necessário modificar o protótipo, repetir os testes e as análises realizadas" (CYBIS; BETIOL; FAUST, 2010).

Com as telas desenvolvidas e com os ajustes das características apontadas nos testes de baixa fidelidade (fontes, legibilidade, funções, etc.), foi aplicado um teste de usabilidade definitivo com protótipos de alta fidelidade. O teste de usabilidade nesta etapa pode ser sistematizado em:
Realização:
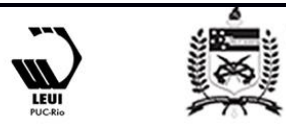
$16^{\circ}$ USIHC - Congresso Internacional de Ergonomia e Usabilidade de Interfaces Humano Computador

CINAHPA | 2017 - Congresso Internacional de Ambientes Hipermídia para Aprendizagem.

a) Análise contextual: verbalização das impressões dos usuários ao usar o aplicativo. Os testes foram conduzidos em lugares próximos do contexto de uso de um aplicativo no cotidiano, para efeito de simulação.

b) Montagem dos testes: refere-se às circunstâncias principais das tarefas para realizar a simulação (usuários, ambiente e funções). A amostragem pesquisada foi semelhante à do teste de baixa fidelidade.

c) Realização dos testes: os usuários foram instruídos sobre o que era o aplicativo e para que servia, bem como foram supervisionados no processo. Através do uso, eles forneceram relatos e deram pontuações para aspectos específicos do aplicativo. Para determinar a nota objetiva no fim do processo, foram aplicadas tabelas sobre as características do aplicativo, sendo essas tabelas baseadas nas propostas de Iida (2005).

d) Análise e avaliação dos testes: com os resultados em mãos, percebeu-se a influência positiva do emprego correto de ícones e cores no uso, porém identificada a falha da ausência de uma função "voltar" para a navegação, o que foi corrigido na versão final. Com uma amostra total de 8 usuários, a média de notas foi 8,33 , considerado "bom".

\subsection{Memorial descritivo}

O memorial descritivo apresenta a interface gráfica final, além de detalhes mais específicos. A interface foi configurada seguindo o estilo do flat design, com layout minimalista e ausência de efeitos tridimensionais, pois de acordo com os testes de uso, o público-alvo demanda clareza e objetividade.
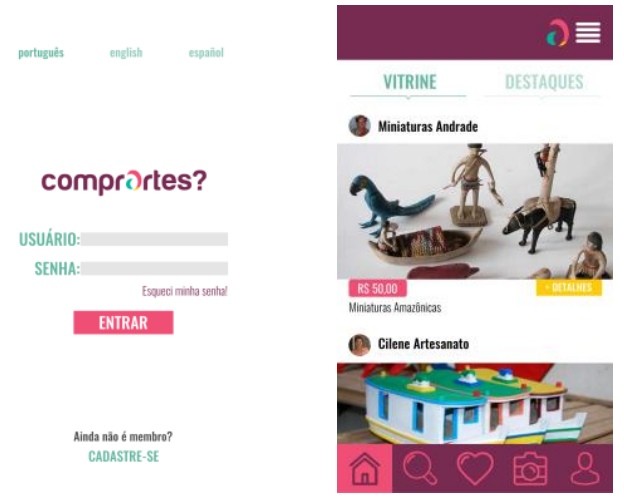

Figura $01-\log$ in Fonte: Autores (2016).

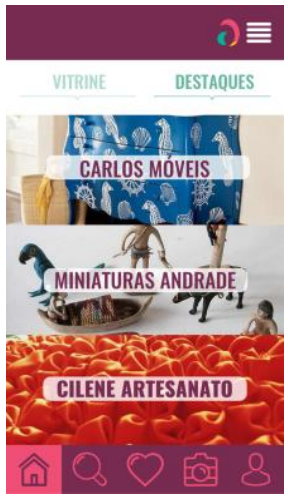

Figura 03 - Destaques Fonte: Autores (2016).
Figura 02 - Vitrine

Fonte: Autores (2016).

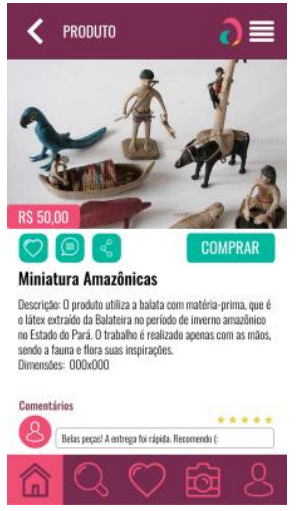

Figura 04 - Produto Fonte: Autores (2016).
Nome: O nome "Comprartes?" surgiu com o intuito de agrupar conceitos primários do projeto: compra + arte; remetendo a questão da própria natureza do aplicativo de e-commerce e com relação aos produtos lá comercializados. O termo no seu geral faz referência ao sentido de questionamento, uma analogia a "Comprastes?", característico do dialeto paraense, além do momento da fala do nome há a relação do duplo sentido de "compra comum" e de "comprar a arte".

\section{comprortes?}

Figura 05 - Marca: Comprartes? Fonte: Autores (2016).

Tipografia: Foi selecionada a fonte Oswald e suas variantes Regular, Medium e Light (Light em descrições de termos para executar ações); fonte de uso livre que é sans-serif, uma vez que não há longas informações textuais que exijam serifa para facilitar o processo de leitura.

Ícones: A definição dos ícones que fazem parte da interface do aplicativo mostraram-se, durante a realização dos testes, de suma importância para comunicação do usuário com a interface. Portanto, a escolha do padrão se baseou na simplicidade e na busca por unidade para que se conserve a identidade e não gere ruídos na interação por meio de imagética que estão no imaginário popular.

Interação com o aplicativo: Algumas funções 
$16^{\circ}$ USIHC - Congresso Internacional de Ergonomia e Usabilidade de Interfaces Humano Computador

presentes no aplicativo utilizam auxílio de ferramentas já existentes, como o Mapas, presente tanto no sistema iOS quanto no Android, para encontrar o endereço das lojas cadastradas, sendo acessado na página de perfil do artesão. As outras interações se dão por realização da compra; possibilidade de comentar nas páginas das lojas avaliando o serviço, e caso avaliação positiva, a loja poderá aparecer em "Destaques"; opção de bate-papo com o artesão, gerando mais confiança ao lidar diretamente com o vendedor; e compartilhamento com outras redes, utilizando recursos do próprio sistema dos smartphones, como o iOS.

Hierarquia de links: Para o projeto, foi necessário hierarquizar de forma coerente e prática para quem for utilizar não ter dificuldades para alcançar seus objetivos. A função da hierarquia no sistema do aplicativo, no caráter de e-commerce, foi situar as funcionalidades de execução de compra, navegação e cadastro para que exista organização de informação textual/pictórica em tamanhos distintos (conforme a relevância do comando) na disposição da interface. Sendo assim, em detrimento dessa hierarquia há funções que podem ser acessadas por diferentes maneiras e os usuários poderão explorá-las sem dificuldades já que o aplicativo se apropria de ícones e funções com estereótipo popular.

\section{Conclusão}

O projeto em questão é um aplicativo que serve como canal entre dois grupos. Portanto, para otimizar o processo de interação entre esses atores sociais, faz-se necessário neste contexto digital apropriar-se de conceitos de usabilidade como requisitos ergonômicos para otimizar esse contato e reduzir erros nas funções, visto que um dos perfis de público-alvo se trata de pessoas com pouca experiência no uso de aplicativos. A ideia surgiu sobre a demanda de um projeto de aplicativo para dispositivos móveis que comportasse em sua essência o tema central "Entre o Rio e a Rua", uma metáfora para a ideia de transferência do meio rural para o urbano bem como a amplitude do alcance de cenários. A partir de técnicas de criatividade, como brainstorming e a criação de painéis semânticos e mentais, foi definido como objetivo proporcionar, através de um e-commerce, a possibilidade de oferecer ao artesanato local um caminho para alcançar outros mercados, auxiliando aos pequenos artesãos a empreender com suas peças, bem como gerar interação entre artesãos/comerciantes e consumidores.

O “Comprartes?" surge com o intuito de aproximar o valor simbólico do artesanato a quem o compra, bem como estimular a produção de produtos artesanais oferecendo ao produtor uma possibilidade dentro de sua realidade de fazer desse ofício sua fonte de renda principal ou alternativa.

\section{BIBLIOGRAFIA}

BAXTER, Mike. Projeto de produto. São Paulo: Ed. Edgard Blücher, 1998.

CYBIS, Walter; HOLTZ, A.; FAUST, Richard. Ergonomia e usabilidade. 2. ed. São Paulo: Novatec, 2010.

DE MORAES, Dijon. Metaprojeto: o design do design. São Paulo: Ed. Edgard Blücher, 2010.

ÉPOCA NEGÓCIOS. Brasil tem 168 milhões de smartphones. 2016. Disponível em:

<https://glo.bo/2q6dko6> Acesso em: 10 de maio de 2017.

GOOGLE INC. Nosso planeta mobile: Brasil. 2012. Disponível em:

$<$ http://services.google.com/fh/files/blogs/our_mob ile_planet_brazil_pt_BR.pdf/> Acesso em: 13 de março de 2016.

IIDA, Itiro. Ergonomia: Projeto e Produção. 2. ed. São Paulo: Ed. Edgard Blücher, 2005.

\section{KRUG, Steve. Não me faça pensar: uma} abordagem de bom senso à usabilidade na Web. 2 . ed. Rio de Janeiro: Alta Books: 2008.

NIEMEYER, Lucy. Elementos de semiótica aplicados ao design. Rio de Janeiro: 2AB, 2003 